ARTICLE OPEN

\title{
Acute dose-dependent effects of lysergic acid diethylamide in a double-blind placebo-controlled study in healthy subjects
}

\author{
Friederike Holze iD $^{1,2}$, Patrick Vizeli iD ${ }^{1,2}$, Laura Ley ${ }^{1,2}$, Felix Müller ${ }^{3}$, Patrick Dolder ${ }^{1,2}$, Melanie Stocker ${ }^{1,2}$, Urs Duthaler $^{1,2}$, \\ Nimmy Varghese ${ }^{3,4}$, Anne Eckert $\mathbb{i}^{3,4}$, Stefan Borgwardt ${ }^{3}$ and Matthias E. Liechti $\mathbb{i}^{1,2}$
}

Growing interest has been seen in using lysergic acid diethylamide (LSD) in psychiatric research and therapy. However, no modern studies have evaluated subjective and autonomic effects of different and pharmaceutically well-defined doses of LSD. We used a double-blind, randomized, placebo-controlled, crossover design in 16 healthy subjects (eight women, eight men) who underwent six $25 \mathrm{~h}$ sessions and received placebo, $\operatorname{LSD}(25,50,100$, and $200 \mu \mathrm{g})$, and $200 \mu \mathrm{g}$ LSD $1 \mathrm{~h}$ after administration of the serotonin 5 hydroxytryptamine-2A $\left(5-\mathrm{HT}_{2 \mathrm{~A}}\right)$ receptor antagonist ketanserin $(40 \mathrm{mg})$. Test days were separated by at least 10 days. Outcome measures included self-rating scales that evaluated subjective effects, autonomic effects, adverse effects, plasma brain-derived neurotrophic factor levels, and pharmacokinetics up to $24 \mathrm{~h}$. The pharmacokinetic-subjective response relationship was evaluated. LSD showed dose-proportional pharmacokinetics and first-order elimination and dose-dependently induced subjective responses starting at the $25 \mu \mathrm{g}$ dose. A ceiling effect was observed for good drug effects at $100 \mu \mathrm{g}$. The $200 \mu \mathrm{g}$ dose of LSD induced greater ego dissolution than the $100 \mu \mathrm{g}$ dose and induced significant anxiety. The average duration of subjective effects increased from 6.7 to $11 \mathrm{~h}$ with increasing doses of 25-200 $\mu \mathrm{g}$. LSD moderately increased blood pressure and heart rate. Ketanserin effectively prevented the response to $200 \mu \mathrm{g}$ LSD. The LSD dose-response curve showed a ceiling effect for subjective good effects, and ego dissolution and anxiety increased further at a dose above $100 \mu \mathrm{g}$. These results may assist with dose finding for future LSD research. The full psychedelic effects of LSD are primarily mediated by serotonin $5-\mathrm{HT}_{2 \mathrm{~A}}$ receptor activation.

Neuropsychopharmacology (2021) 46:537-544; https://doi.org/10.1038/s41386-020-00883-6

\section{INTRODUCTION}

Lysergic acid diethylamide (LSD) is a classic serotonergic psychedelic with a broad history of early psychiatric research and recreational use $[1,2]$. LSD induces a range of complex alterations of the mind that have been shown to depend on serotonin 5-hydroxytryptamine- $2 \mathrm{~A}\left(5-\mathrm{HT}_{2 \mathrm{~A}}\right)$ receptor stimulation [3-5]. Renewed interest has been seen in using LSD in psychiatric research and to assist psychotherapy [6-9]. However, all recent placebo-controlled high-dose studies of LSD used only single doses [4, 10-13]. No recent data are available on the acute effects of different well-defined psychoactive doses of LSD in humans and within the same study. Therefore, the present study evaluated acute subjective and autonomic effects of LSD across a range of relevant doses in healthy subjects. In contrast to previous studies [10-12], we used pharmaceutically well-defined doses of LSD. We verified LSD content uniformity of the doses and performed a pharmaceutical stability test. We comprehensively determined plasma LSD concentrations over time to document each individual exposure to LSD and defined the pharmacokinetics of LSD across all doses. Psychedelics can induce neuroregeneration [14]. Therefore, we also measured plasma brain-derived neurotrophic factor (BDNF) levels as a possible biomarker for neurogenesis [15]. Furthermore, we evaluated the role of $5-\mathrm{HT}_{2 \mathrm{~A}}$ receptors in the acute effects of a high dose of LSD by administering the $5-\mathrm{HT}_{2 \mathrm{~A}}$ receptor antagonist ketanserin prior to the administration of $200 \mu \mathrm{g}$ LSD and compared the acute response to the administration of $200 \mu \mathrm{g}$ LSD alone. Complex acute subjective effects of LSD were determined using validated psychometric instruments that are used internationally and in trials with patients and have been shown to be useful for predicting therapeutic long-term responses [16-19]. We hypothesized that LSD effects would be dosedependent and blocked by ketanserin. The present LSD dose-response data may be useful for dose finding in future LSD research in healthy subjects and patients.

\section{METHODS AND MATERIALS}

Study design

The study used a double-blind, placebo-controlled, crossover design with six experimental test sessions to investigate the responses to (i) placebo, (ii) $25 \mu \mathrm{g}$ LSD, (iii) $50 \mu \mathrm{g}$ LSD, (iv) $100 \mu \mathrm{g}$ LSD, (v) $200 \mu \mathrm{g} \mathrm{LSD}$, and (vi) $200 \mu \mathrm{g}$ LSD $1 \mathrm{~h}$ after ketanserin administration $(40 \mathrm{mg}$ ). Block randomization was used to counterbalance the different dosing conditions. The washout periods between sessions were at least 10 days. The study was conducted in accordance with the Declaration of Helsinki and International Conference on Harmonization Guidelines in Good Clinical Practice and approved by the Ethics Committee of Northwest Switzerland

\footnotetext{
${ }^{1}$ Department of Biomedicine and Department of Clinical Research, Clinical Pharmacology and Toxicology, University Hospital Basel, Basel, Switzerland; ${ }^{2}$ Department of Pharmaceutical Sciences, University of Basel, Basel, Switzerland; ${ }^{3}$ Psychiatric University Hospital, University of Basel, Basel, Switzerland and ${ }^{4}$ Transfaculty Research Platform Molecular and Cognitive Neuroscience, University of Basel, Basel, Switzerland

Correspondence: Matthias E. Liechti (matthias.liechti@usb.ch)
}

Received: 10 June 2020 Revised: 18 September 2020 Accepted: 26 September 2020

Published online: 15 October 2020 
(EKNZ) and Swiss Federal Office for Public Health. The study was registered at ClinicalTrials.gov (NCT03321136).

\section{Participants}

Sixteen healthy subjects (eight men and eight women; mean age \pm SD: $29 \pm 6.4$ years; range: $25-52$ years) were recruited by word of mouth or an advertisement that was posted on the web market platform of the University of Basel. Mean body weight was $69 \mathrm{~kg}$ and 78 and $60 \mathrm{~kg}$ in male and female participants, respectively. Accordingly, doses/body weight of LSD were 1.3-fold higher in men than women. All of the subjects provided written informed consent and were paid for their participation. Drug administration timing did not consider the menstrual cycle in females for practical reasons. Four women used a hormonal contraceptive and one was menopausal. Exclusion criteria were age $<25$ years or $>65$ years, pregnancy (urine pregnancy test at screening and before each test session), personal or family (first-degree relative) history of major psychiatric disorders (assessed by the Semi-structured Clinical Interview for Diagnostic and Statistical Manual of Mental Disorders, 4th edition, Axis I disorders by a trained psychiatrist), the use of medications that may interfere with the study medications (e.g., antidepressants, antipsychotics, and sedatives), chronic or acute physical illness (e.g., abnormal physical exam, electrocardiogram, or hematological and chemical blood analyses), tobacco smoking (>10 cigarettes/day), lifetime prevalence of illicit drug use $>10$ times (except for $\Delta^{9}$-tetrahydrocannabinol), illicit drug use within the last 2 months, and illicit drug use during the study period (determined by urine drug tests). The participants were asked to consume no more than 10 standard alcoholic drinks/ week and have no more than one drink on the day before the test sessions. Six participants had previously used LSD (1-3 times), eight participants had used methylenedioxymethamphetamine (MDMA) (1-5 times), ten participants had previously used a stimulant, including methylphenidate (four participants, 1-2 times), amphetamine (six participants, 1-3 times), and cocaine (two participants, 1-2 times), and one participant had smoked opium (once). Six participants had never used any illicit drugs with the exception of cannabis. Substance use histories are shown in Table S1 in the Supplementary Methods online. Drug of abuse tests performed once during the screening and once during the study in each subject were negative.

\section{Study drugs}

LSD base (>99\% purity; Lipomed AG, Arlesheim, Switzerland) was administered as an oral solution that was produced according to good manufacturing practice in units that contained 100 or $25 \mu \mathrm{g}$ LSD in $1 \mathrm{ml}$ of $96 \%$ ethanol [20]. The exact analytically confirmed LSD content (mean \pm SD) of the 25 and $100 \mu \mathrm{g}$ formulations was $25.7 \pm 0.57 \mu \mathrm{g}$ ( $n=9$ samples) and $98.7 \pm 1.6 \mu \mathrm{g}$ ( $n=9$ samples), respectively. Stability of the formulation for longer than the study period was documented in an identically produced previous batch [20]. One microgram of LSD base that was used in the present study corresponded to $1.25 \mu \mathrm{g}$ LSD tartrate that was used recreationally and in other studies [9, 21]. Ketanserin was obtained as the marketed drug Ketensin ( $20 \mathrm{mg}$, Janssen-Cilag, Leiden, $\mathrm{NL}$ ) and encapsulated with opaque capsules to ensure blinding. Placebo consisted of identical opaque capsules that were filled with mannitol. A double-dummy method was used. The subjects received two capsules and two solutions in each session: (i) two placebo capsules and placebo/placebo solutions, (ii) two placebo capsules and $25 \mu \mathrm{g} \mathrm{LSD} /$ placebo solutions, (iii) two placebo capsules and $25 \mu \mathrm{g} \mathrm{LSD} / 25 \mu \mathrm{g}$ LSD solutions, (iv) two placebo capsules and $100 \mu \mathrm{g} \mathrm{LSD} /$ placebo solutions, (v) two placebo capsules and $100 \mu \mathrm{g}$ LSD/100 $\mu \mathrm{g}$ LSD solutions, and (vi) two ketanserin capsules and $100 \mu \mathrm{g}$ LSD/100 $\mu \mathrm{g}$ LSD solutions. At the end of each session and at the end of the study, the participants were asked to retrospectively guess their treatment assignment.
Study procedures

The study included a screening visit, six $25 \mathrm{~h}$ test sessions (each separated by at least 10 days), and an end-of-study visit. The sessions were conducted in a calm hospital room. Only one research subject and one investigator were present during each test session. The test sessions began at 7:45 a.m. A urine sample was taken to verify abstinence from drugs of abuse, and a urine pregnancy test was performed in women. The subjects then underwent baseline measurements. Ketanserin $(40 \mathrm{mg})$ or placebo was administered at 8:00 a.m. LSD or placebo was administered at 9:00 a.m. The outcome measures were repeatedly assessed for $24 \mathrm{~h}$. Standardized lunches and dinners were served at 1:30 p.m. and 6:00 p.m. respectively. The subjects were never alone during the first $16 \mathrm{~h}$ after drug administration, and the investigator was in a room next to the subject for up to $24 \mathrm{~h}$. The subjects were sent home the next day at 9:15 a.m.

\section{Subjective drug effects}

Subjective effects were assessed repeatedly using visual analog scales (VASs) $[12,13] 1 \mathrm{~h}$ before and 0, 0.5, 1, 1.5, 2, 2.5, 3, 4, 5, 6, 7, $8,9,10,11,12,14,16$, and $24 \mathrm{~h}$ after drug administration. VASs were assessed each time LSD blood concentrations were measured to allow for PK-PD modeling. The Adjective Mood Rating Scale (AMRS) [22] was used $1 \mathrm{~h}$ before and 3, 6, 9, 12, and $24 \mathrm{~h}$ after drug administration. The 5 Dimensions of Altered States of Consciousness (5D-ASC) scale $[23,24]$ was used as the primary outcome measure and was administered $24 \mathrm{~h}$ after drug administration to retrospectively rate peak drug effects. Mystical experiences were assessed $24 \mathrm{~h}$ after drug administration using the States of Consciousness Questionnaire $[25,26]$ that includes the 43-item Mystical Effects Questionnaire (MEQ43) [25], 30-item Mystical Effects Questionnaire (MEQ30) [27], and subscales for "aesthetic experience" and negative "nadir" effects. Subjective effects measurements are described in detail in Supplementary Methods online.

\section{Autonomic and adverse effects}

Blood pressure, heart rate, and tympanic body temperature were repeatedly measured [28]. Adverse effects were assessed $1 \mathrm{~h}$ before and 12 and $24 \mathrm{~h}$ after drug administration using the list of complaints [29].

Plasma BDNF levels

Plasma BDNF levels were measured at baseline and 6, 12, and $24 \mathrm{~h}$ after drug administration using the Biosensis Mature BDNF Rapid ELISA Kit (Thebarton, Australia) [30].

\section{Plasma LSD concentrations}

Blood was collected into lithium heparin tubes. The blood samples were immediately centrifuged, and the plasma was subsequently stored at $-80^{\circ} \mathrm{C}$ until analysis. Plasma concentrations of LSD and $\mathrm{O}-\mathrm{H}-\mathrm{LSD}$ were determined by ultra-high-performance liquid chromatography tandem mass spectrometry with a lower limit of quantification of $5 \mathrm{pg} / \mathrm{ml}$ [20].

Pharmacokinetic analyses and pharmacokinetic-pharmacodynamic modeling

Pharmacokinetic (PK) parameters were estimated using a onecompartment model with first-order input, first-order elimination, and no lag time in Phoenix WinNonlin 6.4 (Certara, Princeton, NJ, USA) [20]. The predicted concentrations of LSD were then used as an input to the pharmacodynamic (PD) model by treating the PK parameters as fixed and using a sigmoid maximum effect model in the classic PK/PD link model module in WinNonlin [20]. The time to onset, time to maximal effect, time to offset, and effect duration were assessed for the model-predicted "any drug effect" VAS effect-time plots after LSD administration using a threshold of $10 \%$ of the maximum individual response using Phoenix WinNonlin 6.4. 
Data analysis

Peak $\left(E_{\max }\right.$ and/or $\left.E_{\min }\right)$ or peak change from baseline $\left(\Delta E_{\max }\right)$ values were determined for repeated measures. The values were then analyzed using repeated-measures analysis of variance, with drug as the within-subjects factor, followed by the Tukey post hoc test. The data were analyzed using Statistica 12 software (StatSoft, Tulsa, OK, USA). The criterion for significance was $p<0.05$. No correction for multiple testing was applied.

\section{RESULTS}

Subjective drug effects

Subjective effects over time on the VAS and AMRS are shown in Fig. 1 and Supplementary Fig. S1, respectively. The corresponding peak responses and statistics are presented in Supplementary Table S2. Alterations of mind and mystical-type effects are shown in Figs. 2, S2, respectively. Statistics are summarized in Supplementary Table $\mathrm{S} 2$.

LSD elicited dose-dependent subjective responses starting at the $25 \mu \mathrm{g}$ dose, which produced significant "any drug effects" compared with placebo $(p<0.05)$. A ceiling effect was reached at the $100 \mu \mathrm{g}$ dose of LSD on most scales (particularly positive subjective effects), with typically no significant differences between the 100 and $200 \mu \mathrm{g}$ doses (Figs. 1, 2, S2). However, the $200 \mu \mathrm{g}$ dose produced significantly greater ego dissolution on the VAS (Fig. 1), greater anxious ego dissolution on the 5DASC (Fig. 2), and greater subjectively negative nadir effects
(Fig. S2) than the $100 \mu \mathrm{g}$ dose (all $p<0.05$ ). Only the $200 \mu \mathrm{g}$ dose and not the $100 \mu \mathrm{g}$ dose induced significant anxiety on the 5DASC (Fig. 2) and AMRS (Supplementary Fig. S1; both $p<0.01$ ). Thus, only ego dissolution and anxiety increased at an LSD dose above $100 \mu \mathrm{g}$. Ketanserin significantly (most $p<0.001$ ) reduced the subjective response to high-dose LSD approximately to levels that were observed with the $25 \mu \mathrm{g}$ dose (Figs. 1, 2, S2). Only a small VAS good drug effect in response to LSD was observed after ketanserin administration, which occurred with a temporal delay compared with the effect of LSD alone (Fig. 1). There was no significant difference in the subjective effects of LSD between LSD-experienced and LSD-naïve participants (Fig. S3).

\section{Autonomic and adverse effects}

Autonomic effects over time and respective peak effects are shown in Fig. 3 and Supplementary Table S2, respectively. Frequently reported adverse effects are presented in Supplementary Table S8. LSD moderately but significantly increased blood pressure at doses of $50 \mu \mathrm{g}$ or higher and heart rate at 100 and $200 \mu \mathrm{g}$ (Fig. 3). LSD had no effect on body temperature. LSD at doses of 100 and $200 \mu \mathrm{g}$ increased the total acute (0-12 h) adverse effects score on the List of Complaints compared with placebo and all other conditions. Ketanserin significantly prevented the LSD-induced heart rate response and transiently reduced the LSDinduced blood pressure response up to $6 \mathrm{~h}$. No severe adverse events were observed.
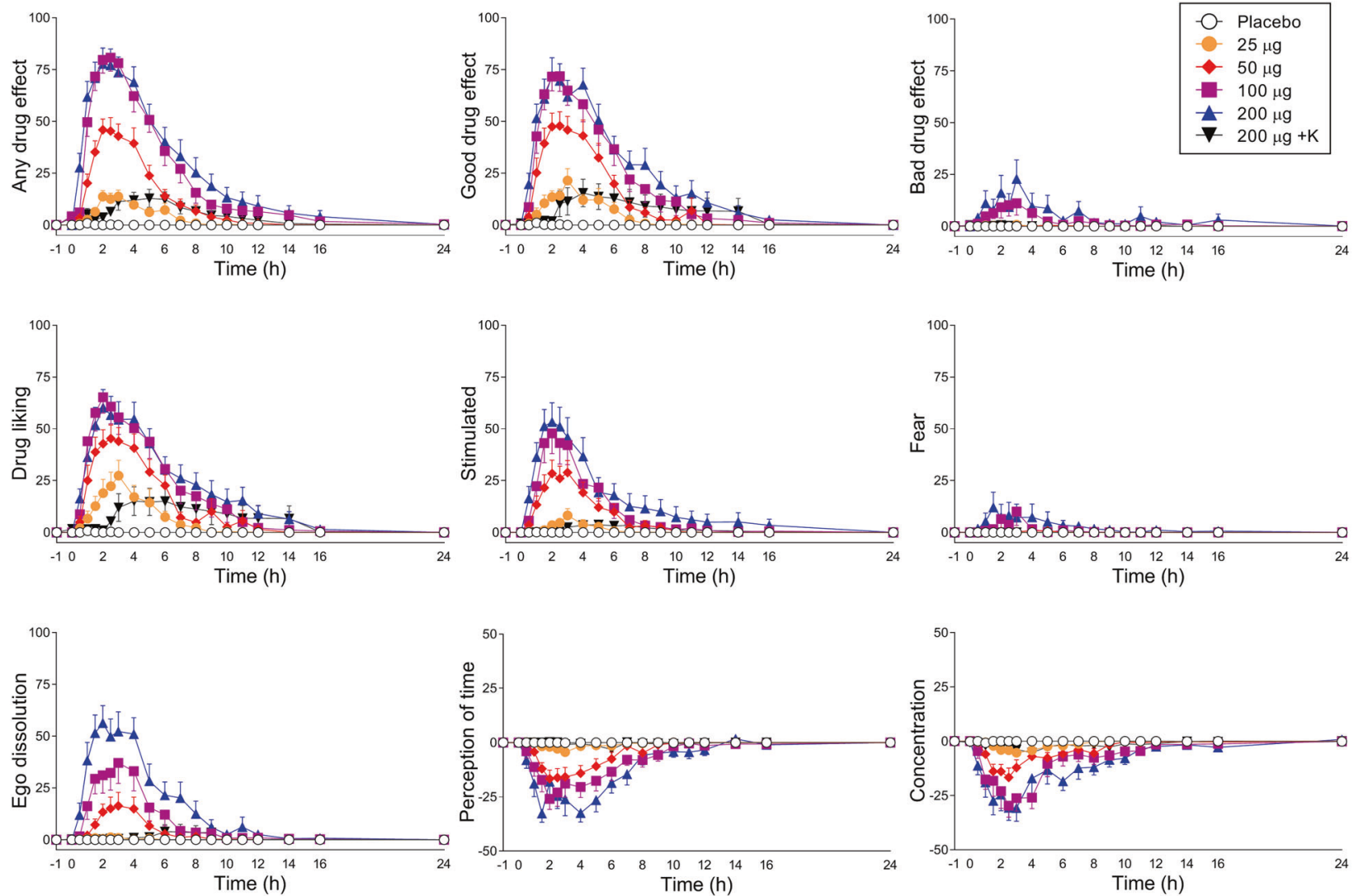

Fig. 1 Acute subjective effects of lysergic acid diethylamide (LSD) over time. LSD $(25-200 \mu g)$ or placebo was administered at $t=0 \mathrm{~h}$. Ketanserin (K) or placebo was administered at $t=-1 \mathrm{~h}$. LSD dose-dependently induced good drug effects, with a maximum effect reached at the $100 \mu \mathrm{g}$ dose. The $200 \mu \mathrm{g}$ dose of LSD did not further increase good drug effects or drug liking compared with the $100 \mu \mathrm{g}$ dose, but it further increased ego dissolution compared with the $100 \mu \mathrm{g}$ dose. Ketanserin markedly reduced the response to the high $200 \mu \mathrm{g}$ dose of LSD approximately to the levels of the $25 \mu \mathrm{g}$ and delayed the remaining small good drug effect and drug liking response compared with LSD alone. The data are expressed as the mean \pm SEM percentage of maximally possible scale scores in 16 subjects. The corresponding maximal responses and statistics are shown in Supplementary Table S2. 

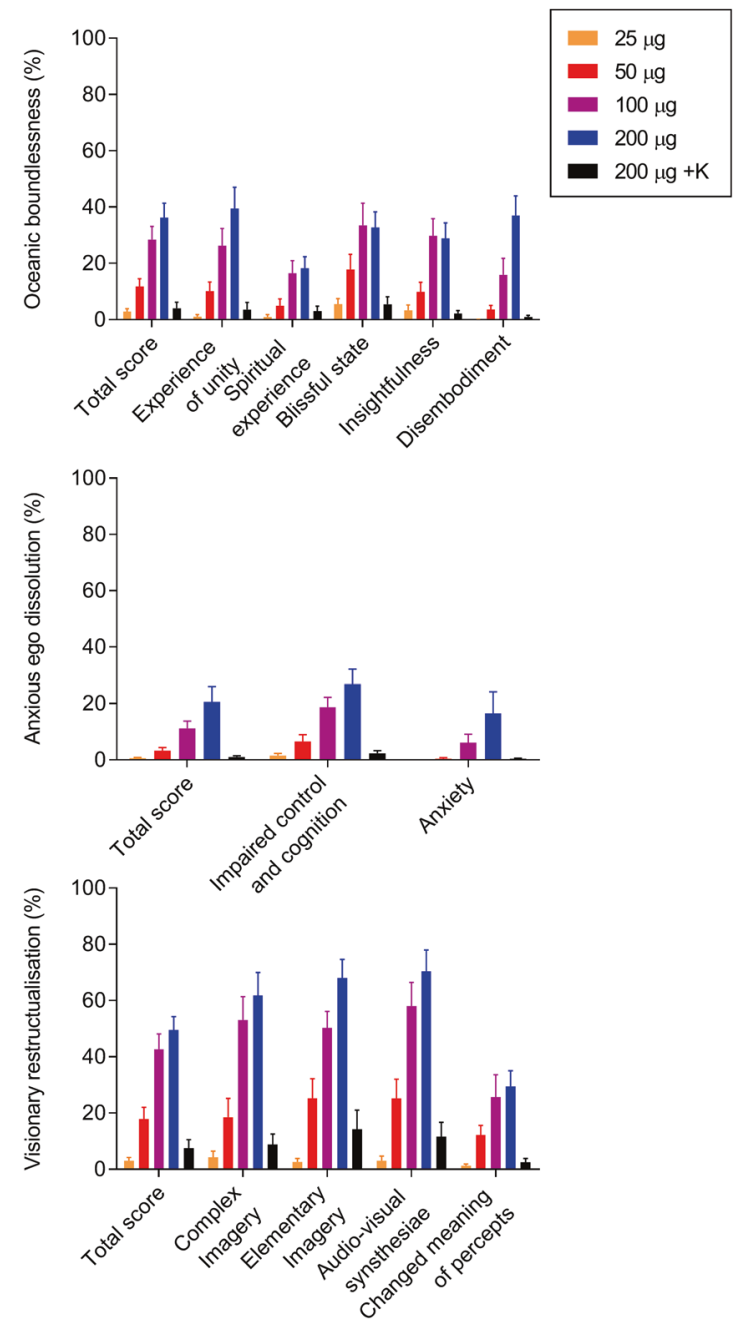

Fig. 2 Acute alterations of mind on the 5 Dimensions of Altered States of Consciousness (5D-ASC) Scale. All lysergic acid diethylamide (LSD) doses $(25-200 \mu \mathrm{g})$ increased "oceanic boundlessness" and "visionary restructuralization." Only the 50, 100, and $200 \mu \mathrm{g}$ doses of LSD significantly influenced "anxious ego dissolution." The dose-response curve showed a ceiling effect for oceanic boundlessness and visionary restructuralization ratings at the $100 \mu \mathrm{g}$ dose. In contrast, ratings of anxious ego dissolution further increased at the $200 \mu \mathrm{g}$ dose compared with the $100 \mu \mathrm{g}$ dose. Additionally, only the $200 \mu \mathrm{g}$ dose and not the $100 \mu \mathrm{g}$ dose induced significant anxiety. Ketanserin markedly reduced the response to the highest LSD dose $(200 \mu \mathrm{g})$ approximately to the level of the $25 \mu \mathrm{g}$ dose. Placebo scores were too low for visualization. The data are expressed as the mean \pm SEM percentage of maximally possible scale scores in 16 subjects. Statistics are shown in Supplementary Table S2.

\section{Plasma BDNF levels}

LSD increased plasma BDNF at the $200 \mu \mathrm{g}$ dose compared with placebo (Supplementary Table S2, Fig. S4).

Pharmacokinetics and pharmacokinetic-pharmacodynamic modeling

Concentrations of LSD and its main metabolite 2-oxo-3-hydroxy LSD (O-H-LSD) could be quantified in all of the subjects, at all doses, and at all time-points. Table 1 shows the PK parameters of LSD. Model-predicted LSD concentrations and effects over time are shown in Fig. 4. Plasma LSD concentrations increased proportionally with increasing doses (Fig. 4). The predicted VAS any drug effects and good drug effects of LSD showed a ceiling

effect at the $100 \mu \mathrm{g}$ dose, and higher bad drug effects and greater ego dissolution were reported at the $200 \mu \mathrm{g}$ dose compared with $100 \mu \mathrm{g}$ (Fig. 4). The time to onset, time to maximal effect, time to offset, and effect duration are shown in Table S3. Summarized, the time to onset of the LSD response decreased, and the time to offset increased, resulting in longer effect durations with higher doses of LSD (Fig. 4, Table S3). Ketanserin had no significant effect on the PKs of LSD (Table 1). PK parameters based on noncompartmental analyses are shown in Supplementary Tables S4, S5. Parameters for the PK-PD link model are summarized in Supplementary Table S6. Corresponding individual data is presented in Figs. S5-S24. There were no significant difference in the PKs or effects of LSD between male and female participants.

\section{Blinding}

Data on the participants' retrospective identification of the LSD dose condition are shown in Supplementary Table S7. Generally, the 100 and $200 \mu \mathrm{g}$ doses were identified as high doses, but these two doses could not be distinguished. The $25 \mu \mathrm{g}$ dose of LSD was distinguished from placebo and identified correctly or as the $50 \mu \mathrm{g}$ dose of LSD by most participants. Ketanserin and LSD together were identified correctly or mistaken as a low dose of LSD but never mistaken for a high dose of LSD.

\section{DISCUSSION}

The present study investigated acute effects of LSD using a range of well-defined doses in healthy subjects. Previous recent studies mostly used LSD products that were not developed according to pharmaceutical standards, as discussed elsewhere [20]. Additionally, we determined plasma LSD concentrations as measures of exposure to the substance in the body that are a prerequisite for a valid dose-finding study. We used LSD doses in the psychedelic effect dose range (25-200 $\mu \mathrm{g}$ of LSD base) that were expected to induce full subjective effects of LSD as previously reported by comparable studies that used single-dose levels [4, 10-12]. Plasma LSD concentrations increased proportionally with increasing doses and decreased according to first-order elimination. The PK parameters were consistent with single-dose studies [20, 31]. A preliminary report of a longer terminal elimination half-life of LSD [32] was not confirmed in the present study. We found no sex differences in LSD concentrations or effects consistent with previous studies using no body weight adjustment of LSD doses $[20,31,32]$.

LSD dose-dependently increased subjective effects that were largely similar to previous studies that used single-dose levels [10$13,26]$. Importantly, a ceiling effect was reached at higher doses of LSD $(>100 \mu \mathrm{g})$ with regard to its positive subjective effects, with no difference in good drug effects between the 100 and $200 \mu \mathrm{g}$ doses. However, the $200 \mu \mathrm{g}$ dose of LSD produced significantly greater ego dissolution and anxious ego dissolution than the $100 \mu \mathrm{g}$ dose. Additionally, only the $200 \mu \mathrm{g}$ dose and not the $100 \mu \mathrm{g}$ dose of LSD-induced significant anxiety. However, doses above $100 \mu \mathrm{g}$ may be used if the goal is to induce the experience of ego dissolution or disembodiment. These experiences, however, were produced at doses that also produced more anxiety compared with lower doses. LSD doses of 100 and $200 \mu \mathrm{g}$ were both subjectively identified as high doses but could not be subjectively distinguished with certainty from each other. Both of these doses can clearly be considered full psychedelic doses and have previously been investigated in healthy subjects $[11,12]$. No previous studies directly compared LSD doses of 100 and $200 \mu \mathrm{g}$. In contrast to the present findings, we previously reported moderately greater effects of a $200 \mu \mathrm{g}$ dose of LSD in one study [12] compared with $100 \mu \mathrm{g}$ in another study [11]. Specifically, $200 \mu \mathrm{g}$ LSD produced significantly greater total scores on the 5DASC scale, including higher ratings of blissful state, insightfulness, and changed meaning of percepts compared with $100 \mu \mathrm{g}$ [26]. 

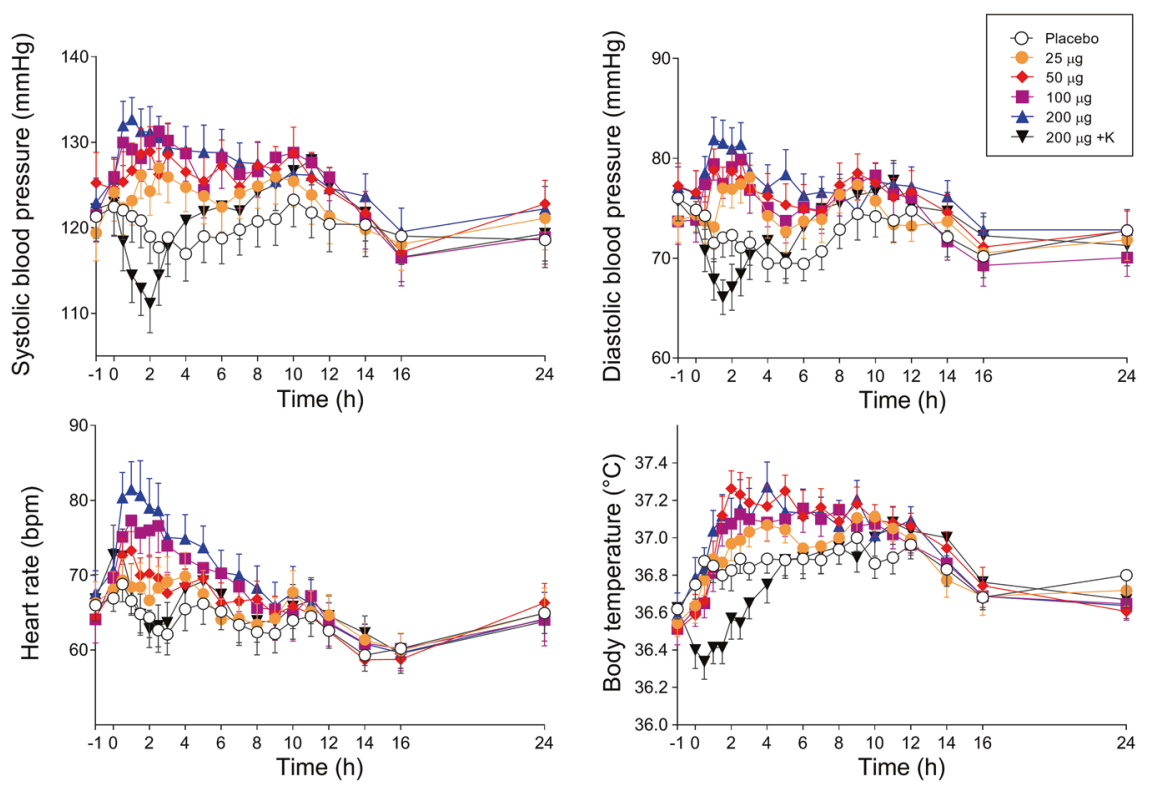

Fig. 3 Acute autonomic effects. Doses of 50, 100, and $200 \mu$ g lysergic acid diethylamide (LSD) similarly increased systolic blood pressure compared with placebo. The 100 and $200 \mu \mathrm{g}$ doses similarly increased diastolic blood pressure and heart rate compared with placebo. Ketanserin (K) transiently decreased blood pressure, heart rate, and body temperature, with a delayed increase to the levels that were reached after the administration of LSD alone. LSD (25-200 $\mu \mathrm{g})$ or placebo was administered at $t=0 \mathrm{~h}$. Ketanserin (K) or placebo was administered at $t=-1 \mathrm{~h}$. The data are expressed as the mean \pm SEM in 16 subjects. Maximal effects and statistics are shown in Supplementary Table S2.

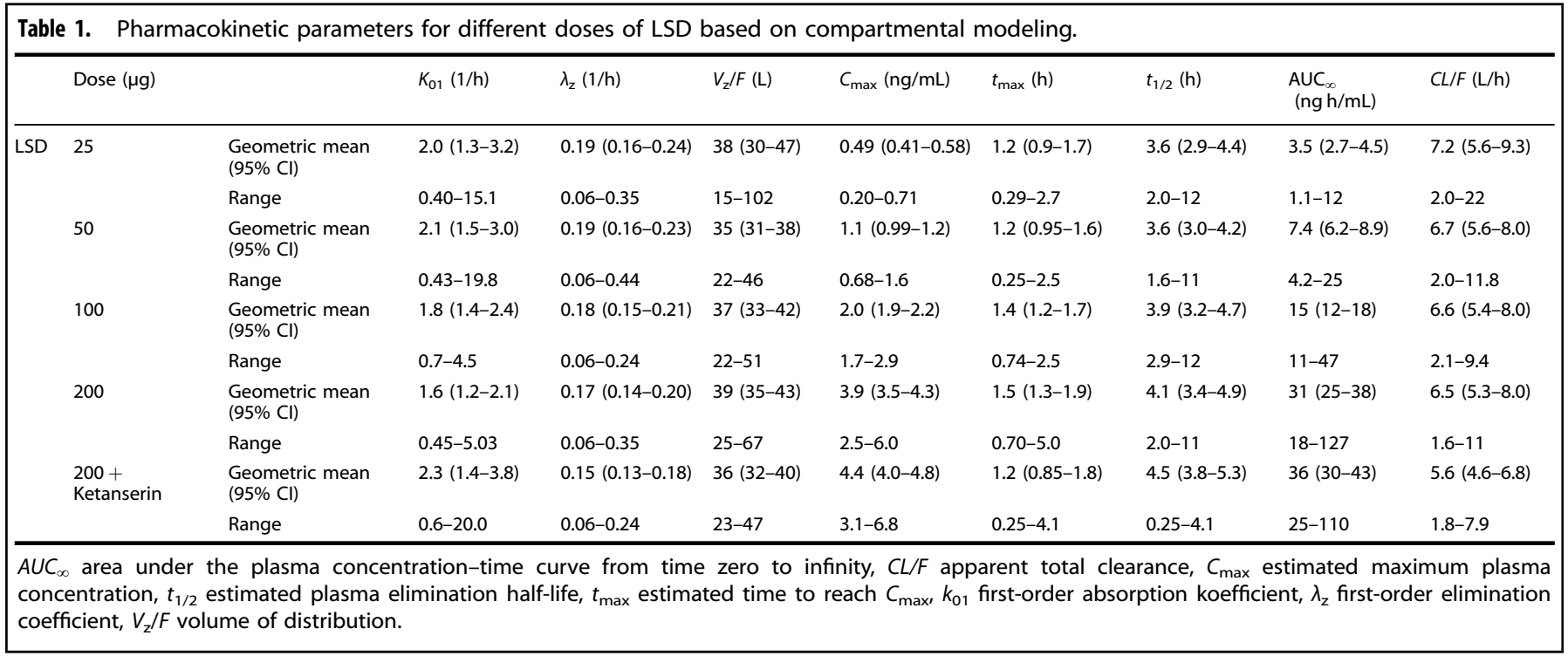

In a previous study, the $200 \mu \mathrm{g}$ dose of LSD also produced higher ratings of good drug effects, bad drug effects, fear, open, and trust on the VAS compared with $100 \mu \mathrm{g}$ [11]. There are two explanations for the absence of an LSD dose response for good drug effects in the present study compared with our previous studies. First, the true doses that were used in the previous studies were $60-70$ and $150 \mu \mathrm{g}$ rather than the reported 100 and $200 \mu \mathrm{g}$ doses because of the use of an unstable formulation with a lower LSD content, as discussed elsewhere [20]. Second, the past comparison was between different subjects and studies [11, 26], whereas the present study used valid within-subject and within-study comparisons. In the present study, we observed a ceiling effect on the dose-response curve. Considering that the previously reported $200 \mu \mathrm{g}$ dose likely contained only $150 \mu \mathrm{g}$ of active LSD, additional positive effects may be reached with $150 \mu \mathrm{g}$ compared with
$100 \mu \mathrm{g}$. This possibility remains to be tested. One of our recent studies also used an analytically confirmed LSD dose of $100 \mu \mathrm{g}$, which produced scores on the VAS and 5D-ASC scale that were nominally higher than those that were reported after $100 \mu \mathrm{g}$ administration in the present study [13] and more similar to the scores that were reported herein after $200 \mu \mathrm{g}$ administration. Altogether, the available data support the view that mainly high acute positive effects of LSD can be induced at a $100 \mu \mathrm{g}$ dose of LSD base. Therefore, we speculate that a dose of $100 \mu \mathrm{g}$ of LSD may be selected for the treatment of depression or anxiety where higher Oceanic Boundlessness and lower anxiety ratings acutely induced by psychedelics predicted better treatment efficacy [1619]. The $50 \mu \mathrm{g}$ dose that was used in the present study also produced substantial positive mood effects and notably only very small and nonsignificant anxious ego dissolution, with no anxiety. 

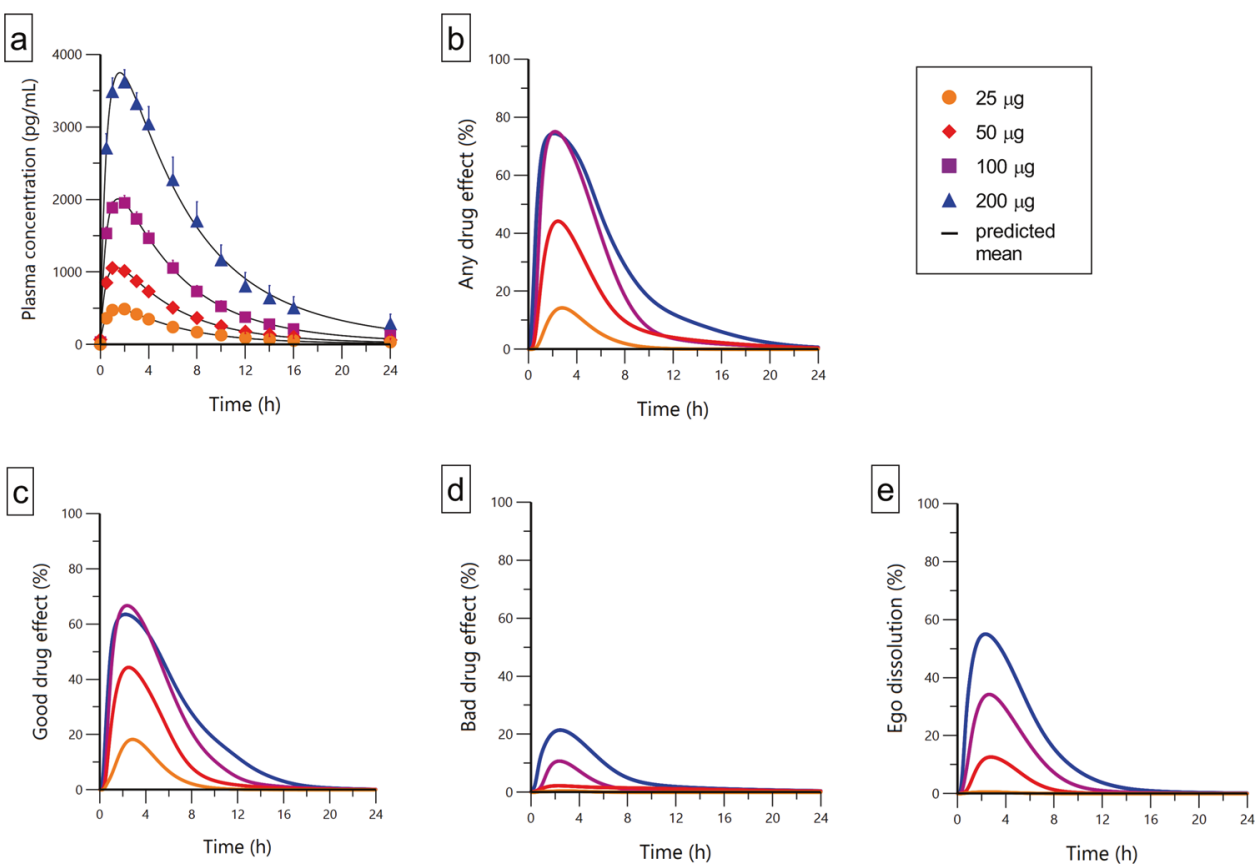

Fig. 4 Pharmacokinetics and subjective effects of lysergic acid diethylamide (LSD). a Plasma LSD concentration-time curves for 25, 50, 100, and $200 \mu \mathrm{g}$ doses of LSD. b-e LSD effect-time curves for Visual Analog Scale ratings (0-100\%) of (b) "any drug effect," (c) "good drug effect," (d) "bad drug effect," and (e) "ego dissolution." LSD administration resulted in dose-proportional increases in plasma concentrations of LSD, but subjective good drug effects reached a ceiling at the $100 \mu \mathrm{g}$ dose and did not further increase at the $200 \mu \mathrm{g}$ dose. In contrast, bad drug effects and ego dissolution increased further at the $200 \mu \mathrm{g}$ dose compared with $100 \mu \mathrm{g}$. Therefore, LSD doses higher than $100 \mu \mathrm{g}$ produced no further increases in good drug effects but more ego dissolution and anxiety. The data are expressed as the mean \pm SEM in 16 subjects. LSD was administered at $t=0 \mathrm{~h}$. The lines represent the means of the individual pharmacokinetic-pharmacodynamic (subjective effect) model predictions.

Thus, the $50 \mu \mathrm{g}$ dose may be useful for inducing a moderately intense and predominantly positive psychedelic experience. This low psychedelic dose would likely be a good starting dose to be used in patients with no previous experience with psychedelics or in subjects who are considered to be more sensitive to the effects of psychedelics [33].

In the present study, LSD produced moderate elevations of arterial blood pressure and heart rate starting at the $50 \mu \mathrm{g}$ dose that were largely similar to the effects of 100 and $200 \mu g$. Similarly, previous studies that used pharmaceutically not wellcharacterized doses of 100 and $200 \mu \mathrm{g}$ LSD found no difference in the acute cardiostimulant effects of these doses [11]. A previous study in patients did not observe any increases in blood pressure using a non-confirmed dose of $200 \mu \mathrm{g}$ of LSD [34]. Methylenedioxymethamphetamine clearly has more pronounced cardiostimulant effects and a less favorable overall physical safety profile than LSD $[13,35]$. In contrast, the psychotropic effects of LSD are significantly greater compared with MDMA [13].

In the present study, administration of the $5-\mathrm{HT}_{2 \mathrm{~A}}$ receptor antagonist ketanserin $1 \mathrm{~h}$ before LSD administration markedly reduced the subjective response to the $200 \mu \mathrm{g}$ LSD dose to levels that were similar to the $25 \mu \mathrm{g}$ dose. Retrospective reports showed that ketanserin and LSD together were identified correctly by the participants or mistaken as a low dose of LSD but never mistaken for a high dose of LSD. The present findings are consistent with a previous study in which ketanserin administration prior to the administration of $100 \mu \mathrm{g}$ LSD almost completely prevented the acute effects of LSD [4]. These findings support the view that LSD primarily produces its acute psychedelic effects in humans via 5$\mathrm{HT}_{2 \mathrm{~A}}$ receptor activation $[3-5,36]$, which was also shown for a high and fully psychedelic dose of LSD. Ketanserin also prevented acute adverse effects of LSD and the LSD-induced heart rate response. However, the weak blood pressure-elevating effects of LSD were only transiently prevented by ketanserin and reappeared later during the LSD response. This observation is consistent with the relatively short half-life of ketanserin (i.e., $2 \mathrm{~h}$ ) during the first $1-9 \mathrm{~h}$ following administration [37, 38].

In the present study, $200 \mu \mathrm{g}$ LSD significantly increased BDNF plasma concentration compared with placebo with a peak at $6 \mathrm{~h}$. Additionally, there were nonsignificant increases in plasma BDNF after lower doses of LSD or after ketanserin with LSD. In previous studies, $100 \mu \mathrm{g}$ LSD had no effect on BDNF plasma levels [13] up to $5 \mathrm{~h}$ while the psychedelic ayahuasca increased BDNF at 2 days. Further, higher BDNF levels were associated with lower depression ratings after administration of ayahuasca [39]. More research is needed to define the time course of the BDNF response and whether there is a link between psychedelics, BDNF, and the antidepressant response [39].

In addition to providing dose-response data on full psychedelic doses of LSD, the present study further characterized the effects of small doses of $\operatorname{LSD}[9,40]$. The lowest dose that was used in the present study contained $25 \mu \mathrm{g}$ of LSD base. This dose produced subjective "any drug effects" that were significantly different from placebo and retrospectively identified as LSD by the majority $(>85 \%)$ of the participants. Very low doses of LSD have typically been referred to as "microdoses." Psychedelic microdoses have been postulated to have beneficial prolonged effects on mood while producing no or only minimal acute adverse subjective effects [40-43]. Positive long-term effects of psychedelic microdoses remain to be documented [42], and remaining unclear are the LSD doses that actually have no acute subjective effects and thus could be considered microdoses [40]. Very low to low doses of LSD were recently studied in two placebo-controlled trials $[9,21,44,45]$. One study also provided preliminary PK data [45]. In older healthy volunteers, $5-20 \mu \mathrm{g}$ of LSD tartrate produced small but significant linear dose-dependent increases in ratings of all of the following: subjective drug effects, vigilance reduction, dizziness, and changes in body feeling $[21,45]$. The frequency of 
adverse effects of LSD at doses up to $20 \mu \mathrm{g}$ was not different from placebo. The mean plasma $C_{\max }$ values of LSD (non-compartmental analyses) were $0.44 \mathrm{ng} / \mathrm{ml}(n=8)$ after the administration of $20 \mu \mathrm{g}$ of LSD tartrate [45] and $0.51 \mathrm{ng} / \mathrm{ml}$ after the administration of $25 \mu \mathrm{g}$ of LSD base in the present study, indicating comparable dose-proportional peak concentrations. The previous study included younger healthy subjects and found dosedependent increases in subjective ratings of "feel drug" and "like drug" on VASs and on the 5D-ASC scale after the administration of $6.5,13$, and $26 \mu \mathrm{g}$ of LSD tartrate [9]. Notably, a $26 \mu \mathrm{g}$ dose of LSD tartrate would be lower than the $25 \mu \mathrm{g}$ dose of LSD base (i.e., $31 \mu \mathrm{g}$ of LSD tartrate equivalent) that was used in the present study. Nevertheless, the $26 \mu \mathrm{g}$ dose of LSD tartrate produced significant effects on the 5D-ASC scale compared with placebo and nominally greater ratings on the 5D-ASC subscales than the $25 \mu \mathrm{g}$ dose that was used in the present study. Unfortunately, no plasma LSD concentration data have been published for the $26 \mu \mathrm{g}$ dose of LSD tartrate [9]. Therefore, a comparison of drug exposures between this previous study and the present study to further validate the dose comparison is not possible. Altogether, the available data from these controlled studies, including the present study that used very small and small doses of LSD, indicate that the $25 \mu \mathrm{g}$ dose of LSD is clearly acutely psychoactive in the majority of subjects. Doses in the range of 21-30 $\mu \mathrm{g}$ of LSD base may thus be considered "minidoses" rather than "microdoses." Doses of LSD base in the 1-20 $\mathrm{g}$ range may be considered "microdoses" but need further study. However, these doses may already elicit small dose-dependent subjective effects, although they are unlikely to relevantly impair cognition or produce adverse effects [9, 21, 44, 45].

Overall, the present dose-response study characterized a range of LSD doses. Based on the available data, the following dosing terminology may be useful for future LSD research: "microdose" $(1-20 \mu \mathrm{g})$, "minidose" $(21-30 \mu \mathrm{g})$, and "psychedelic dose" (>30 $\mu \mathrm{g})$. Within the psychedelic LSD dose range, good effects likely predominate at doses of $30-100 \mu \mathrm{g}$ (good-effect dose), whereas ego dissolution and anxiety increase at doses above $100 \mu \mathrm{g}$ (egodissolution dose).

The present study has numerous strengths. Four different doses of LSD were used within subjects and compared with placebo under double-blind conditions in a controlled laboratory setting. A ketanserin-LSD condition was also included to elucidate the mechanism of action of LSD and enhance blinding between the different conditions. We also included equal numbers of male and female participants and used internationally established standardized and validated psychometric outcome measures. The doses of LSD were pharmaceutically well-characterized, and plasma LSD concentrations and PK parameters were determined up to $24 \mathrm{~h}$ for all doses. Notwithstanding these strengths, the present study also has limitations. The study used a highly controlled setting and included only healthy subjects. Additionally, participants willing to participate in LSD research are likely to have positive expectations and some participants had past substance experiences. Thus, subjects in different environments and patients with psychiatric disorders may respond differently to LSD.

\section{CONCLUSION}

We characterized the effects of LSD at different doses to support the dosing of LSD for research and LSD-assisted therapy. LSD exhibited dose-proportional PKs and first-order elimination. It produced significant dose-dependent subjective responses starting at the $25 \mu \mathrm{g}$ dose. A ceiling effect was observed for good drug effects at the $100 \mu \mathrm{g}$ dose. The $200 \mu \mathrm{g}$ dose induced more ego dissolution but also more anxiety than the $100 \mu \mathrm{g}$ dose. These results may assist with dose finding for future LSD research. Ketanserin almost completely prevented the response to the high
$(200 \mu \mathrm{g})$ dose of LSD, thus confirming the critical role of $5-\mathrm{HT}_{2 \mathrm{~A}}$ receptors in mediating psychedelic effects of LSD.

\section{FUNDING AND DISCLOSURE}

This work was supported by the Swiss National Science Foundation (grant no. 32003B_185111 to MEL). MEL is a consultant for Mind Medicine, Inc. The other authors declare no competing interests. Knowhow and data associated with this work and owned by the University Hospital Basel were licensed by Mind Medicine, Inc., after study completion. Mind Medicine, Inc. had no role in financing, planning, or conducting the present study or the present publication. Open Access funding provided by Universität Basel (Universitätsbibliothek Basel).

\section{ACKNOWLEDGEMENTS}

The authors thank Raoul Dürig and Toya Caluori for their helping with conducting the study and Beatrice Vetter for performing the plasma LSD concentration determination. The authors acknowledge the assistance of Michael Arends for proofreading the paper.

\section{AUTHOR CONTRIBUTIONS}

$\mathrm{FH}, \mathrm{PV}, \mathrm{PD}, \mathrm{FM}$, and MEL designed the research. FH, UD, PV, LL, NV, FM, AE, MS, and SB performed the research. FH, UD, PV, and MEL analyzed the data. FH and MEL wrote the paper with input from all of the other authors. All authors gave final approval to the paper.

\section{ADDITIONAL INFORMATION}

Supplementary Information accompanies this paper at (https://doi.org/10.1038/ s41386-020-00883-6).

Publisher's note Springer Nature remains neutral with regard to jurisdictional claims in published maps and institutional affiliations.

\section{REFERENCES}

1. Passie T, Halpern JH, Stichtenoth DO, Emrich HM, Hintzen A. The pharmacology of lysergic acid diethylamide: a review. CNS Neurosci Ther. 2008;14:295-314.

2. Nichols DE. Dark classics in chemical neuroscience: lysergic acid diethylamide (LSD). ACS Chem Neurosci. 2018:9:2331-43.

3. Preller KH, Burt JB, Ji JL, Schleifer $\mathrm{CH}$, Adkinson BD, Stampfli $\mathrm{P}$, et al. Changes in global and thalamic brain connectivity in LSD-induced altered states of consciousness are attributable to the 5- $\mathrm{HT}_{2 \mathrm{~A}}$ receptor. Elife. 2018;7:e35082.

4. Preller KH, Herdener M, Pokorny $T$, Planzer $A$, Kraehenmann $R$, Stämpfli $P$, et al. The fabric of meaning and subjective effects in LSD-induced states depend on serotonin 2A receptor activation. Curr Biol. 2017;27:451-7.

5. Kraehenmann R, Pokorny D, Vollenweider L, Preller KH, Pokorny T, Seifritz E, et al. Dreamlike effects of LSD on waking imagery in humans depend on serotonin $2 \mathrm{~A}$ receptor activation. Psychopharmacology. 2017;234:2031-46.

6. Liechti ME. Modern clinical research on LSD. Neuropsychopharmacology 2017;42:2114-27.

7. Nichols DE, Johnson MW, Nichols CD. Psychedelics as medicines: an emerging new paradigm. Clin Pharmacol Ther. 2017;101:209-19.

8. Carhart-Harris RL, Goodwin GM. The therapeutic potential of psychedelic drugs: past, present, and future. Neuropsychopharmacology. 2017;42:2105-13.

9. Bershad AK, Schepers ST, Bremmer MP, Lee R, de Wit H. Acute subjective and behavioral effects of microdoses of lysergic acid diethylamide in healthy human volunteers. Biol Psychiatry. 2019;86:792-800.

10. Carhart-Harris RL, Kaelen M, Bolstridge M, Williams TM, Williams LT, Underwood R, et al. The paradoxical psychological effects of lysergic acid diethylamide (LSD). Psychol Med. 2016;46:1379-90.

11. Dolder PC, Schmid Y, Mueller F, Borgwardt S, Liechti ME. LSD acutely impairs fear recognition and enhances emotional empathy and sociality. Neuropsychopharmacology. 2016;41:2638-46.

12. Schmid Y, Enzler F, Gasser P, Grouzmann E, Preller KH, Vollenweider FX, et al. Acute effects of lysergic acid diethylamide in healthy subjects. Biol Psychiatry. 2015;78:544-53.

13. Holze F, Vizeli P, Muller F, Ley L, Duerig R, Varghese N, et al. Distinct acute effects of LSD, MDMA, and D-amphetamine in healthy subjects. Neuropsychopharmacology. 2020;45:462-71. 
14. Ly C, Greb AC, Cameron LP, Wong JM, Barragan EV, Wilson PC, et al. Psychedelics promote structural and functional neural plasticity. Cell Rep. 2018;23:3170-82.

15. Haile CN, Murrough JW, losifescu DV, Chang LC, Al Jurdi RK, Foulkes A, et al. Plasma brain derived neurotrophic factor (BDNF) and response to ketamine in treatment-resistant depression. Int J Neuropsychopharmacol. 2014;17:331-6.

16. Roseman L, Nutt DJ, Carhart-Harris RL. Quality of acute psychedelic experience predicts therapeutic efficacy of psilocybin for treatment-resistant depression. Front Pharmacol. 2017:8:974

17. Ross S, Bossis A, Guss J, Agin-Liebes G, Malone T, Cohen B, et al. Rapid and sustained symptom reduction following psilocybin treatment for anxiety and depression in patients with life-threatening cancer: a randomized controlled trial. J Psychopharmacol. 2016;30:1165-80.

18. Griffiths RR, Johnson MW, Carducci MA, Umbricht A, Richards WA, Richards BD, et al. Psilocybin produces substantial and sustained decreases in depression and anxiety in patients with life-threatening cancer: a randomized double-blind trial. J Psychopharmacol. 2016;30:1181-97.

19. Garcia-Romeu A, Griffiths RR, Johnson MW. Psilocybin-occasioned mystical experiences in the treatment of tobacco addiction. Curr Drug Abuse Rev. 2015;7:157-64.

20. Holze F, Duthaler U, Vizeli P, Muller F, Borgwardt S, Liechti ME. Pharmacokinetics and subjective effects of a novel oral LSD formulation in healthy subjects. $\mathrm{Br} J$ Clin Pharmacol. 2019;85:1474-83.

21. Yanakieva S, Polychroni N, Family N, Williams LTJ, Luke DP, Terhune DB. The effects of microdose LSD on time perception: a randomised, double-blind, placebo-controlled trial. Psychopharmacology. 2019;236:1159-70.

22. Janke W, Debus G. Die Eigenschaftswörterliste. Göttingen: Hogrefe; 1978.

23. Dittrich A. The standardized psychometric assessment of altered states of consciousness (ASCs) in humans. Pharmacopsychiatry. 1998;31:80-4.

24. Studerus E, Gamma A, Vollenweider FX. Psychometric evaluation of the altered states of consciousness rating scale (OAV). PLoS ONE. 2010;5:e12412.

25. Griffiths RR, Richards WA, McCann U, Jesse R. Psilocybin can occasion mysticaltype experiences having substantial and sustained personal meaning and spiritual significance. Psychopharmacology. 2006;187:268-83. discussion 84-92

26. Liechti ME, Dolder PC, Schmid Y. Alterations in conciousness and mystical-type experiences after acute LSD in humans. Psychopharmacology. 2017;234:1499-510.

27. Barrett FS, Johnson MW, Griffiths RR. Validation of the revised Mystical Experience Questionnaire in experimental sessions with psilocybin. J Psychopharmacol. 2015;29:1182-90.

28. Hysek CM, Vollenweider FX, Liechti ME. Effects of a $\beta$-blocker on the cardiovascular response to MDMA (ecstasy). Emerg Med J. 2010;27:586-9.

29. Zerssen DV. Die Beschwerden-Liste. Münchener informationssystem. München: Psychis; 1976.

30. Akimoto H, Oshima S, Sugiyama T, Negishi A, Nemoto T, Kobayashi D. Changes in brain metabolites related to stress resilience: Metabolomic analysis of the hippocampus in a rat model of depression. Behav Brain Res. 2019;359:342-52.

31. Dolder PC, Schmid Y, Steuer AE, Kraemer T, Rentsch KM, Hammann F, et al. Pharmacokinetics and pharmacodynamics of lysergic acid diethylamide in healthy subjects. Clin Pharmacokinet. 2017;56:1219-30.

32. Dolder PC, Schmid Y, Haschke M, Rentsch KM, Liechti ME. Pharmacokinetics and concentration-effect relationship of oral LSD in humans. Int J Neuropsychopharmacol. 2015;19:pyv072.
33. Studerus E, Gamma A, Kometer M, Vollenweider FX. Prediction of psilocybin response in healthy volunteers. PLoS ONE. 2012;7:e30800.

34. Gasser P, Holstein D, Michel Y, Doblin R, Yazar-Klosinski B, Passie T, et al. Safety and efficacy of lysergic acid diethylamide-assisted psychotherapy for anxiety associated with life-threatening diseases. J Nerv Ment Dis. 2014;202:513-20.

35. Vizeli $P$, Liechti ME. Safety pharmacology of acute MDMA administration in healthy subjects. J Psychopharmacol. 2017;31:576-88.

36. Barrett FS, Preller $\mathrm{KH}$, Herdener $\mathrm{M}$, Janata $\mathrm{P}$, Vollenweider FX. Serotonin $2 \mathrm{~A}$ receptor signaling underlies $L S D$-induced alteration of the neural response to dynamic changes in music. Cereb Cortex. 2018;28:3939-50.

37. Persson B, Heykants J, Hedner T. Clinical pharmacokinetics of ketanserin. Clin Pharmacokinet. 1991;20:263-79.

38. Reimann IW, Okonkwo PO, Klotz U. Pharmacokinetics of ketanserin in man. Eur J Clin Pharmacol. 1983;25:73-6.

39. de Almeida RN, Galvao ACM, da Silva FS, Silva E, Palhano-Fontes F, Maia-deOliveira JP, et al. Modulation of serum brain-derived neurotrophic factor by a single dose of ayahuasca: observation from a randomized controlled trial. Front Psychol. 2019;10:1234.

40. Kuypers KP, Ng L, Erritzoe D, Knudsen GM, Nichols CD, Nichols DE, et al. Microdosing psychedelics: more questions than answers? An overview and suggestions for future research. J Psychopharmacol. 2019;33:1039-57.

41. Fadiman J, Korb S. Might microdosing psychedelics be safe and beneficial? an initial exploration. J Psychoact Drugs. 2019;51:118-22.

42. Passie T. The science of microdosing psychedelics. London: Psychedelic Press; 2019.

43. Hutten N, Mason NL, Dolder PC, Kuypers KPC. Motives and side-effects of microdosing with psychedelics among users. Int J Neuropsychopharmacol. 2019;22:426-34.

44. Bershad AK, Preller KH, Lee R, Keedy S, Wren-Jarvis J, Bremmer MP, et al. Preliminary report on the effects of a low dose of LSD on resting-state amygdala functional connectivity. Biol Psychiatry Cogn Neurosci Neuroimaging. 2020;5:461-7.

45. Family N, Maillet EL, Williams LTJ, Krediet E, Carhart-Harris RL, Williams TM, et al. Safety, tolerability, pharmacokinetics, and pharmacodynamics of low dose lysergic acid diethylamide (LSD) in healthy older volunteers. Psychopharmacology. 2020;237:841-53.

Open Access This article is licensed under a Creative Commons Attribution 4.0 International License, which permits use, sharing, adaptation, distribution and reproduction in any medium or format, as long as you give appropriate credit to the original author(s) and the source, provide a link to the Creative Commons license, and indicate if changes were made. The images or other third party material in this article are included in the article's Creative Commons license, unless indicated otherwise in a credit line to the material. If material is not included in the article's Creative Commons license and your intended use is not permitted by statutory regulation or exceeds the permitted use, you will need to obtain permission directly from the copyright holder. To view a copy of this license, visit http://creativecommons. org/licenses/by/4.0/.

(c) The Author(s) 2020 